\title{
EL PAISAJE DE LA CUENCA LECHERA CENTRAL ARGENTINA Construcción metodológica de la Investigación
}

\author{
Autor: Arq. César Torres \\ INVIHAB-CEUR-CONICET \\ Directora de la Investigación en curso: Dra. Arq. Isabel Martínez de San Vicente \\ E-mail: ct_86@hotmail.com
}

\section{RESUMEN}

Se reconoce un marco global complejo y de alta competitividad económica con gran influencia en los paradigmas de ordenamiento territorial y de gestión del paisaje, en el cual la identidad regional es cuestionada frente a la reestructuración productiva mundial en marcha. La Cuenca Lechera Central Argentina, tanto por sus características intrínsecas como por una suma de elementos naturales y antrópicos contenidos, requeriría de una clara estrategia territorial desde un abordaje multiescalar ajustado a su propia realidad. A su vez, la tarea de repensar el territorio y el paisaje de la cuenca no implicaría sólo un barrido de varias escalas: para poder reflexionar sobre una alternativa de desarrollo económico, cultural, regional y sustentable se torna imperioso abrazar la construcción de un enfoque propio que rescate también diversos aportes teóricos y metodológicos, con el claro objeto de articular de forma creativa sus saberes y experiencias en un planteo integrador.

Palabras clave: Ordenamiento Territorial - Paisaje - Regiones productivas

\begin{abstract}
A complex global setting of high economic competitiveness is recognized, with great influence on the paradigms of territorial planning and landscape management, and in which regional identity is questioned in front of the ongoing worldwide productive restructuring. The Argentinian Central Dairy Basin, as much for its intrinsic features as for the amount of natural and anthropic elements it contains, would require a clear territorial strategy from a multi-scale approach which matches its own reality. In turn, the task of re-thinking the territory and the landscape of the basin would not only imply scanning through several scales: in order to reflect on an alternative of economic, cultural, regional and sustainable development it becomes imperative to embrace the construction of a self-approach that also rescues diverse theoretical and methodological contributions, with the clear purpose of creatively assembling their knowledge and experiences into an integrating outline.
\end{abstract}

Keywords: Territorial Planning - Landscape - Productive regions 


\section{INTRODUCCIÓN}

Pensar nuestros propios territorios implica una prerrogativa compleja que adquiere especial ímpetu en un marco global tanto de incertidumbre como de crisis y recesión económicas. Dicho contexto no sólo implica pensar en alternativas para combatir, en el corto plazo, dichas problemáticas, sino que además plantea el desafío de reproponer la manera en que pensamos el desarrollo a largo término de nuestras regiones productivas. Históricamente, la actividad lechera en la Cuenca Lechera Central Argentina (en adelante, CLCA) no ha estado escindida de los cambios en los paradigmas económico-productivos que se han sucedido a escala provincial, nacional y global. Emprender este recorrido histórico posibilitaría, entre otras cosas, hallar claves sobre la actual crisis lechera que experimenta la cuenca. En la comprensión de las relaciones entre el territorio, su paisaje y sus actividades productivas subyace la esencia que permitiría repensar el ordenamiento territorial futuro de la región.

Para ello, el desafío también radica en encontrar los puentes entre aquellos abordajes que estudian la triada mencionada, integrando miradas complementarias en pos de un discurso metodológico propio. Consideramos conveniente, antes de indagar sobre los aspectos metodológicos de esta investigación, hacer un breve recorrido por los interrogantes que originaron este trabajo, presentando sus hipótesis y objetivos, así como sus alcances (las contribuciones esperadas) y finalmente, una caracterización sintética del objeto de estudio en cuestión. Se presentará brevemente, por otro lado, el aporte de un estudio de caso (el del paisaje cultural de Cinque Terre), intentando demostrar su utilidad a la hora de ensayar una metodología propia primigenia que estimamos luego mejorar y pulir para aplicar al caso de estudio principal, el de la CLCA.

Además, previo a avanzar con esta presentación, estimamos importante aclarar que la misma es parte de una investigación doctoral que se desarrolla en el Instituto de Investigación de la Vivienda y el Hábitat (INVIHAB) dependiente del Centro de Estudios Urbanos y Regionales (CEUR), y que a su vez responde al Consejo Nacional de Investigaciones Científicas y Técnicas (CONICET). Además, esta tesis integra el Doctorado en Estudios Urbano-Regionales que se dicta en convenio binacional entre la Universidad Nacional de Córdoba (UNC) en Argentina y la Bauhaus Universität Weimar (BUW) en Alemania. Por otra parte, el avance del trabajo posee el siguiente estado: tanto su marco teórico como planteo metodológico están prácticamente completos, mientras que se han hecho avances parciales en el análisis y valoración de datos secundarios para la consecución de las tareas planteadas para algunos objetivos de la presente investigación.

\subsection{Pregunta de Investigación e Hipótesis}

¿De qué manera ha contribuido la actividad productiva lechera a modelar la actual configuración del territorio de la CLCA desde el año 1856 a la fecha? De esta pregunta inicial aventuramos dos supuestos, uno principal y otro complementario:

a) Por un lado, se ha conformado en su territorio un paisaje productivo de carácter cultural, regional, histórico y complejo.

b) Por el otro, la historia de la actividad productiva de la CLCA es la historia misma de su territorio: dentro de su profundo reconocimiento y construcción en tanto objeto de estudio radican las claves para su reproposición.

\subsection{Objetivo Central}

Esta investigación pretende contribuir al conocimiento sobre el modo en que el paisaje de la Cuenca Lechera Central Argentina (CLCA) evolucionó en relación a las actividades que se han sucedido en su territorio desde 1856 a la fecha (en particular, la lechería) y que han condicionado su configuración espacial, en términos tanto físicos como socioculturales; y de este modo generar un insumo para la elaboración de lineamientos, programas y planes en el marco de un futuro proyecto territorial integral para la región.

\subsection{Objetivos Particulares}

Del objetivo central se desprenden, a su vez, una serie de objetivos específicos, a saber: 
1. Historizar y analizar el proceso de construcción del paisaje de la CLCA a partir del reconocimiento de las improntas naturales y antrópicas que definen su estructura territorial, y que contribuyeron a construir su actual configuración.

2. Verificar la incidencia de las actividades productivas en relación a la configuración y conformación del paisaje de la CLCA en el período que va desde mediados del siglo XIX a la actualidad, identificando y valorando además las vinculaciones entre el paisaje productivo y el patrimonio regional en él contenidos.

3. Detectar y caracterizar los diversos componentes del paisaje de la CLCA, sus dinámicas y el patrimonio natural y cultural emergente, verificando procesos de continuidad o quiebre en el mismo.

4. Ensayar una síntesis territorial de la CLCA en función de los aspectos naturales, culturales y productivos que definieron históricamente su paisaje, explorando integralmente las posibilidades de su aprovechamiento en términos de ordenamiento y de desarrollo ambiental, sociocultural y económico-productivo.

\subsection{Los alcances de la presente investigación}

Entendemos que la reestructuración productiva es un fenómeno reciente que provoca que las regiones productivas deban encontrar alternativas para desarrollarse sin desatender sus paisajes. Ante la incertidumbre que estos procesos desencadenan, la única certeza territorial parece residir en la propia identidad; ante la fragilidad del escenario internacional, la fortaleza parece brotar de la cultura local; ante la depredación de recursos y el cambio climático en curso, prima el interés por proteger el propio ambiente.

Se persiguen, así, diferentes fines: desde un punto de vista del desarrollo económico regional, se busca generar una alternativa original que tenga en cuenta el complejo fenómeno de reestructuración productiva global actualmente en marcha. Sería interesante utilizar los recursos atesorados en el paisaje al servicio de la mejora de la educación y de la calidad de vida de los habitantes de la región, incorporando al actual paradigma laboral productivo el complemento del turismo cultural. En ese marco, la reafirmación de la identidad de la CLCA y su proyección hacia otras escalas probablemente impulsarían un renovado sentimiento de arraigo de las personas hacia su territorio.

Desde una perspectiva ambiental, se procura hallar modos alternativos de resolver la tensión urbano/rural, valorando el rol de bordes urbanos, cinturones verdes y corredores ecológicos en un contexto actual de creciente depredación del soporte territorial y de mayor indefinición sobre usos del suelo que se encuentran en conflicto. En esta línea, sería provechoso colaborar con una nueva conciencia, nueva visión, nueva manera más comprometida de relacionarse el ser humano con su medio natural a partir del conocimiento profundo del territorio y sus problemáticas.

Esta investigación también tiene el propósito de ser un insumo importante en caso de realizarse un proyecto territorial integral para la CLCA y constituir así la base para la confección futura de lineamientos y planes para la región. De este modo, se espera realizar una contribución a los saberes específicos del ordenamiento territorial con base en la investigación del caso particular de la CLCA que pudiere servir de detonante para que nuevas investigaciones sean encaradas en otras regiones del país donde se detecten problemáticas y potencialidades similares.

\subsection{El Objeto de Estudio: La Cuenca Lechera Central Argentina}

Problematizar sobre el territorio y el paisaje de la CLCA implica definir en primera instancia ciertas nociones básicas: para comenzar, interesante es rastrear la etimología misma de la palabra cuenca, ${ }^{1}$ para luego entender el compuesto cuenca productiva. ${ }^{2}$ En todo caso, encontramos que son las ciencias naturales las que definen la conceptualización: la cuenca productiva implica ciertos elementos nucleados dentro de un mismo territorio, si se

\footnotetext{
${ }^{1}$ Según la Real Academia Española, la palabra proviene del latín "concha" y hace referencia a un territorio que se encuentra rodeado de alturas con sus aguas discurriendo todas a un mismo espejo de agua. Este criterio hidrológico es el más ampliamente encontrado para definirla.

${ }^{2}$ Una cuenca productiva es aquella que comprende a productores primarios que se nuclean territorialmente para producir un bien o una materia prima alimentaria a partir de la explotación o del uso de un recurso natural.
} 
quiere, "convergiendo hacia". De allí la similitud con la palabra cuenca. Pero, ¿cómo se hace extensiva esta idea a una cuenca lechera? ${ }^{3}$ Podemos afirmar que, en este caso, una actividad productiva particularizada (la lechería) es la que define las características y el funcionamiento de gran parte de la economía de la cuenca estudiada. Dicho esto, otro punto a considerar es que la CLCA no es única en su tipo en nuestro país. De hecho, existen múltiples cuencas lecheras, de distintas dimensiones y con ciertas particularidades cada una, pero que en general poseen ciertos rasgos en común: los más notorios de ellos, historias compartidas y la ubicación geográfica dentro de la llanura pampeana.

Tras esta introducción, procederemos a caracterizar brevemente a la CLCA. La región se ubica en el centro de Argentina, entre Santa Fe y Córdoba (abarcando los Departamentos de Las Colonias y Castellanos, el centrosur de San Cristóbal y San Justo, y el centro-norte de San Martín y San Jerónimo; y zonas de la provincia de Córdoba), y es delimitada al este por el Río Salado. Posee gran cantidad de tambos e infraestructura relacionada a la lechería, como varias empresas lácteas de distinta importancia. Se desarrollan a su vez en su territorio otras actividades productivas, como la ganadería y la agricultura, industrias y servicios; y se encuentran importantes centros urbanos (Rafaela, Sunchales y Esperanza en Santa Fe; San Francisco en Córdoba). La cuenca presenta una geografía productiva que combina vastas praderas con polos industriales y de alta tecnología, así como las actividades de servicios en sus centros urbanos. Además del gran aporte productivo y de la capacidad de empleo que generan los tambos y toda la cadena de industrialización láctea, la región cuenta con uno de los mayores stocks de ganado bovino de cría de la Argentina. La actividad ganadera se complementa con emprendimientos porcinos, apícolas, y otros. La cultura emprendedora regional es un valor que se materializa en la empresa familiar, la cual es parte fundamental del necesario diálogo urbano-rural que se da en la cuenca.

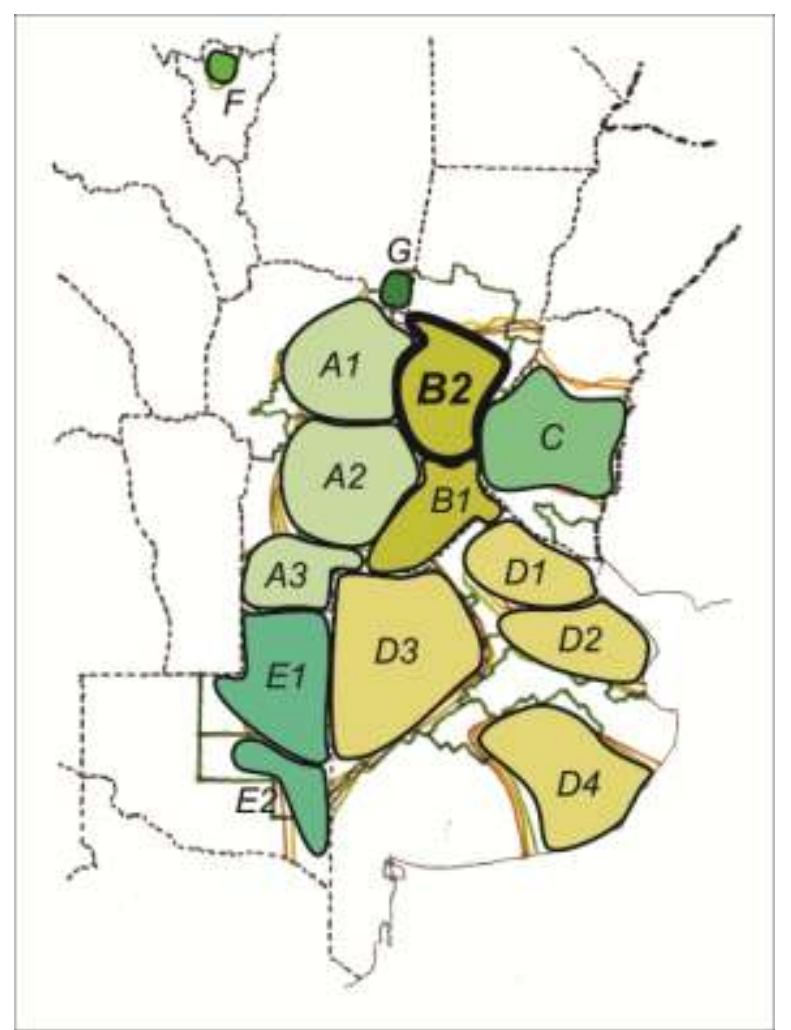

Figura 1. La CLCA en el concierto de las cuencas lecheras argentinas. Delimitación propuesta aproximada en función de la superposición de los datos analizados de varios autores y con criterio exclusivamente productivo-económico. Fuente: elaboración propia.

\footnotetext{
${ }^{3}$ Una cuenca lechera hace referencia a un espacio rural regional marcado por la presencia densa de estructuras de la producción lechera (tambos, cremerías, queserías, e importantes agroindustrias) donde a su vez se desarrollan pujantes centros urbanos (de diferentes jerarquías y grados de especialización funcional) que establecen fuertes lazos con dicho entorno rural. La concentración y el predominio de la producción de leche por sobre otras actividades productivas definen así el $A D N$ del paisaje en cuestión.
} 
Para poder delimitar a la CLCA del resto de cuencas lecheras del país (Figura 1) recurrimos a varias fuentes: Marino, Castignani \& Arzubi; SAGPyA (Secretaría de Agricultura, Ganadería y Pesca de la Nación); el Instituto de Investigaciones Económicas de la Bolsa de Comercio de Córdoba; y Delrío \& Fernández. Entre las cuencas lecheras pampeanas quedan delimitadas, por provincias: en Córdoba: A1 (Noreste), A2 (Villa María) y A3 (Sur); en Santa Fe: B1 (Sur), B2 (Central Argentina); en Entre Ríos: C (Entrerriana); en Buenos Aires: D1 (Abasto Norte), D2 (Abasto Sur), D3 (Oeste), D4 (Mar y Sierras); y en La Pampa: E1 (Centro Norte), E2 (Sur). Mientras que entre las cuencas lecheras exopampeanas quedan delimitadas, por provincias: en Tucumán: $F$ (Trancas); y en Santiago del Estero: G (Rivadavia).

\section{ABORDAJE METODOLÓGICO}

\subsection{Características generales y Enfoques de Partida}

Al tratarse de una investigación cualitativa explorativa, la cual tiene vocación de abordar métodos descriptivos e interpretativos, se hace necesario aclarar que este trabajo apela desde un momento inicial a los conocimientos y técnicas de múltiples saberes y disciplinas. $Y$ todo ello porque plantear la problemática actual del territorio y el paisaje productivo implica revisar aportes diversos. La construcción de un enfoque propio se realiza entonces desde la reinterpretación y la reformulación de postulados y métodos de dichos abordajes; pero además, este proceso no es encarado de manera estanca y finita, sino que se va nutriendo y revisando conforme la investigación continúa su camino. Realizada esta aclaración, podemos aseverar que todas las aportaciones de partida para este trabajo doctoral pueden ligarse a dos miradas fundamentales, que de alguna manera recogen los estudios particulares de cada uno de los enfoques: hablamos del ordenamiento y proyecto territorial por un lado (si posamos el foco sobre el territorio), y el paisaje cultural por el otro (al estudiar el paisaje). Podemos observar estas interrelaciones en la Figura 2, en la cual se sintetizan las metodologías examinadas.

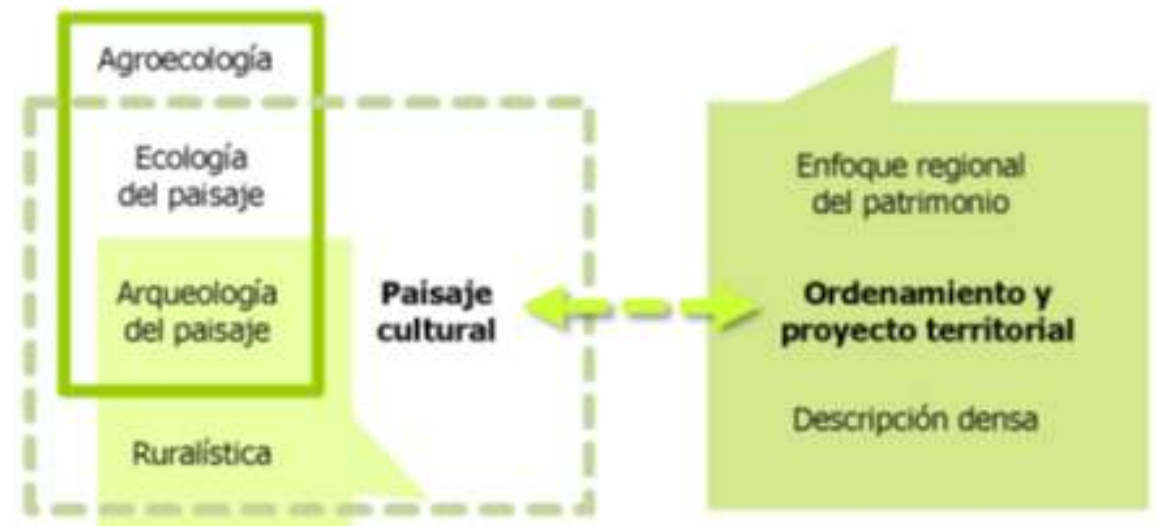

Figura 2. Agrupamiento y nexos entre los enfoques de partida de la investigación. Fuente: elaboración propia.

Encontramos además que, antes de proceder a caracterizar los enfoques arriba mapeados, se torna de gran ayuda poder localizar los canales de discusión en torno a paisaje y territorio. $^{5}$

\footnotetext{
${ }^{4}$ Resultado de una transformación colectiva de la naturaleza y de la proyección cultural de una sociedad en un determinado espacio, entendido como producto inacabado y en evolución permanente (Díaz Terreno, 2013). El paisaje existe como unidad en tanto hay un sujeto que lo vivencia: el valor que se atribuye a su configuración es entonces claramente cultural. "El paisaje constituye un valioso patrimonio natural y cultural de las diferentes sociedades, referente de la identidad regional y local de los asentamientos urbanos y, a su vez, puede ser un importante recurso para el desarrollo socio-económico de éstos. Es además un indicador del desarrollo sostenible (...), como resultado de la acumulación histórica de la intervención del ser humano sobre el territorio" (Argos Proyectos Educativos S.L., 2009, p. 5).

${ }^{5}$ El territorio se encontraría compuesto más por flujos, ejes y nudos que por extensiones y obstáculos (Corboz, 2004). El territorio es, además, inherente a todo proceso histórico. Las relaciones sociales, al ser espacial o geográficamente mediadas, son compuestas de manera indisociable por el territorio (Haesbaert, 2007). La población ocupa el territorio, establece con el mismo una relación de ordenación y hasta de planificación. El territorio termina siendo objeto constante de construcción, como artefacto y como producto (Corboz, 2004). Su apropiación refleja siempre intenciones, por lo tanto se puede decir que el territorio es un proyecto para el cual también la población genera un imaginario colectivo. "Al ser un proyecto, el territorio está semantizado. Es susceptible de discurso. Tiene un nombre (...) El territorio tiene una forma. Mejor, es una forma" (Corboz, 2004, p. 28).
} 


\subsection{El debate alrededor del Paisaje}

La primera pista de la discusión se ubica en torno a paisajes de territorios fuertemente transformados que han sufrido presiones del avance de la urbanización pero también de un intenso uso rural, en un marco de creciente fragmentación del territorio. Estaríamos frente a una "crisis de identidad y legibilidad" del paisaje, la que implicaría nuevos desafíos conceptuales y metodológicos, obligando a reinventar la "dramaturgia del paisaje" (Nogué, 2007). En efecto, el paisaje adquiere relevancia territorial, a raíz de su valor socioeconómico. ${ }^{6}$ Luego, por su carácter histórico, identitario y cultural, intervenido por el ser humano al realizar sus diversas actividades e influenciando así cuestiones referidas a la identidad cultural local. En tercer lugar, la degradación y pérdida de diversidad a la que se ha visto envuelto el territorio (y por ende, el paisaje) en los años recientes, implica que su estado y su planificación no pueden ser desatendidos. Los paradigmas actuales valoran tanto los paisajes excepcionales como aquellos que se consideran ordinarios, los cuales, aunque a simple vista no serían de gran interés, en realidad son depositarios de enorme cuantía patrimonial, tanto material como intangible (Argos Proyectos Educativos S.L., 2009).

El paisaje y sus valores adquieren renovado interés en la década de 1960. La creciente población urbana que visita áreas rurales con el fin de recrearse adquiere un sentido de preocupación estética y medioambiental por el mismo. Se observa entonces que existían diferencias perceptuales entre aquellos que visitan una región y sus paisajes en un itinerario estratégico y aquellos que residen en dichos territorios. Esta información será la base para los estudios morfológico-perceptuales de, entre otros, Kevin Lynch, quien plantea la aprehensión paisajística a partir de un sistema de elementos fácilmente reconocibles (nodos, hitos, áreas, bordes, sendas). Pero además, se analiza que la imaginación colectiva y las respuestas conductuales sobre la percepción de los paisajes resultan ser complejas, y se le presta así especial atención al papel de las asociaciones de imágenes culturales, políticas y sociales que logran establecer los individuos para con sus territorios (Cosgrove, 2002).

Por otro lado, Cosgrove apunta que el debate que rodea al paisaje tiene una historia compleja en el marco de la geografía cultural. En la mirada tradicional de esta disciplina, el ojo omnipotente del profesional formado debía ser capaz de diferenciar lo cultural de lo natural tanto en la morfología del paisaje como en sus representaciones (dando cuenta de las formas humanas y físicas tal como aparecían en los mapas topográficos). En ese sentido, recientemente ha sido cuestionado el paradigma occidental de la Modernidad que iguala a la visión con el conocimiento y la razón. Las críticas han llovido desde diversas posturas, desde el posestructuralismo al feminismo, que consideran que la tradición racionalista posee un muy marcado sesgo patriarcal, masculinista y sobre todo, eurocéntrico. Todo ello conduce a un replanteo actual de las relaciones entre paisaje, geografía y sentido de la vista. Los enfoques así resultantes son históricos, con especial énfasis en las experiencias culturales diversas en un espacio que se percibe como relativo.

Hoy en día se introducen en el estudio del paisaje otras temáticas relacionadas a la expresión, la actuación, la identidad y también el conflicto. Así, los estudios poscoloniales examinan aspectos culturales del colonialismo a partir del paisaje, mientras que otras investigaciones esbozan enfoques menos normativos sobre relaciones entre el cuerpo y la naturaleza en un marco de espacios de género, sexuados y personas con capacidades diferentes (Cosgrove, 2002). La crítica enfatiza el carácter dual de la visión, pero sobre todo, las posibilidades individuales para cuestionar las propias elaboraciones en torno al paisaje. Además, hoy se reconoce que la visión humana no puede escindirse de otros sentidos, así como de cuestiones de índole cognitiva, afectiva y conductual.

Cosgrove también coloca en el tablero de discusión el rol histórico de los adelantos tecnológicos en la apropiación paisajística. Explotar la naturaleza implicó además poder registrarla, y en los últimos siglos el interés por medir exactamente los espacios naturales productivos ha tenido por detrás las exigencias de la propiedad privada y de los mercados internacionales. Así, las técnicas topográficas y la elaboración de cartas y mapas catastrales fueron fundamentales no sólo para medir el propio territorio, sino para colonizar y poder apropiarse de paisajes en áreas de colonización. "En el paisaje, las destrezas y técnicas del topógrafo, del cartógrafo, del planificador y del artista se solapan y a menudo fueron los mismos individuos los que las han puesto en práctica, algo que era especialmente cierto en el caso del arte y la cartografía militares" (Cosgrove,

\footnotetext{
${ }^{6}$ El paisaje es un recurso relativamente escaso y de gran utilidad a la hora de pensar en alternativas para crear empleo y generar riqueza, y si la sociedad lo percibe como recurso entonces es un elemento candidato a ser gestionado.
} 
2002, p. 75). A medida que la visión fue mecanizándose, "tecnologizándose", las relaciones entre técnicas de recopilación de imágenes y su representación se han ido perfeccionando. Hoy disponemos de fotos satelitales y de simulaciones interactivas que permiten una aproximación muy detallada al paisaje y sus formas, y que están disponibles para un amplio rango de personas (desde el planificador hasta el ciudadano común).

\subsection{Enfoques vinculados al estudio del Paisaje}

Tras el surgimiento de la agricultura y su incorporación al paisaje, la principal dificultad ha sido siempre la de pretender "restituir" la realidad de un paisaje "natural" que ya no es tal, por lo cual tratar de separar paisaje natural de paisaje social sería conceptualmente infundado y sesgado (González Villaescusa, 1996). En efecto, las relaciones entre los artefactos humanos y la naturaleza utilizan el salvoconducto de la noción de paisaje para ser repensadas (Díaz Terreno, 2013). En concordancia con estas posturas es que emerge la perspectiva de los paisajes culturales. ${ }^{7}$ La preservación de dichos paisajes se alcanzaría a través de la "transformación" y la "creatividad" y no a partir de un mero conservacionismo del patrimonio. La mejor forma de actuar sería aquella que mejor "lea", "interprete" y "valore" el territorio y sus recursos (Sabaté Bel, 2010). "La preservación de ámbitos naturales y sociales, el diseño de redes de recursos territoriales, el enriquecimiento de la base productiva local, la proyección de la región hacia otros contextos, la autovaloración por parte del poblador local de sus oficios, tradiciones y patrimonio material acumulado" y "la posibilidad de vislumbrar un futuro posible para la región" serían los aspectos que impulsan esta metodología (Díaz Terreno, 2013, p. 337). A este nuevo impulso metodológico y disciplinar se le suma el apoyo de numerosas experiencias realizadas recientemente, sobre todo en el ámbito europeo y latinoamericano, con resultados que evidentemente alientan a la profundización y reformulación de estrategias propias. El todavía novedoso carácter del enfoque precisa de revisiones constantes.

En correlato con lo explicado en las líneas anteriores, Corboz muestra un claro posicionamiento frente al tema, aún sin mencionar a los paisajes culturales como tales, al verificar el interés creciente que los paisajes agrarios vienen despertando en los investigadores en los últimos años. Así, reconoce que son necesarias nuevas bases para retomar el estudio regional: una lectura del territorio completamente reorientada, que buscaría identificar e interpretar las huellas aún presentes de procesos y de proyectos territoriales extintos. Huellas que serían las que fundamentan las intervenciones de los planificadores del territorio. La larga y lenta estratificación del territorio debe reconocerse para poder pensar en intervenirlo: el espesor del mismo es entonces restituido. A su vez, las huellas y mutaciones pueden ser utilizadas como "elementos, puntos de apoyo, acentos, estimulantes de nuestra propia planificación" (Corboz, 2004, p. 34).

Al pensar en la planificación del territorio, urge reconocer aquellos abordajes que han contribuido a alimentar el de los paisajes culturales. El primero de ellos lo constituye la ruralística. ${ }^{8}$ Tradicionalmente, el estudio del territorio ha sido colocado en un orden de prioridad secundario respecto del de las ciudades y los sistemas urbanos. Dicha relegación se ha hecho extensiva también, al ser el territorio la entidad mayor que lo abarca, al espacio rural. En ese sentido, los nuevos retos y esfuerzos comenzarían a focalizarse en la construcción de una disciplina rigurosa sobre dicho territorio no urbano. La ruralística sostiene que el tratamiento del suelo no urbanizable debería pensarse sumando otros mecanismos de obtención y gestión de tierras. No obstante, sería necesario encarar un gran esfuerzo de renovación disciplinar en la que haciendo una valoración de la discusión urbano/rural se vislumbren "nuevos retos", como lo son afrontar planes territoriales y renovar el bagaje para intervenir el paisaje rural (Sabaté Bel, 2003).

Con ligazones a la anterior mirada también podemos destacar los aportes de la arqueología del paisaje. ${ }^{9}$ Resulta imperioso reconocer la labor de los geógrafos al hacer sus aportes a la historia agraria de los territorios (González Villaescusa, 1996), brindando respuestas a la reconstrucción del medio bajo los efectos de la acción

\footnotetext{
${ }^{7}$ Ámbito geográfico asociado a eventos, actividades y personajes históricos, con una clara carga de valores culturales y estéticos; en otras palabras, huella del trabajo humano sobre el territorio a lo largo de un tiempo histórico.

${ }^{8}$ La ruralística tiene como objeto "lograr la comprensión de las escalas, estructuras, formas y lógicas de producción y transformación del espacio rural, como también de su capacidad de soporte" (Díaz Terreno, 2013, p. 30). Interesan tanto los factores naturales que van interviniendo en la explicación de la forma territorial como los elementos visibles que describen dicha realidad y le otorgan historicidad (Díaz Terreno, 2013).

${ }^{9}$ La misma generaría una metodología para la reconstrucción del marco natural y de la interacción que las sociedades mantienen con el medio. El reconocimiento de las prácticas de cultivo y de sus estructuras, así como de los procesos de trabajo, debería inscribirse entonces en el marco de dicho enfoque (González Villaescusa, 1996).
} 
del hombre. Entre ellas se incluyen cuestiones referidas a una visión general que exige no sólo la reconstrucción del soporte natural y de la interacción entre aquél y las sociedades que lo transforman, sino también la comprensión de las estructuras económicas y del comportamiento de aquellas sociedades que lo han generado (Díaz Terreno, 2013). De todos modos, el mismo autor reconoce que la noción de paisaje vendría a ofrecer una mirada más global y profunda, y se estaría en condiciones de brindar una metodología para acceder a la elucidación de la interacción entre naturaleza y sociedad que no se limite a la descripción de las estructuras agrarias, sino que aspire a entender el funcionamiento de un sistema (Díaz Terreno, 2013).

Distinta mirada sobre el tema recoge la ecología del paisaje. ${ }^{10} \mathrm{El}$ término fue acuñado por el geógrafo Carl Troll a finales de la década de 1930, con la clara intención de buscar un complemento a las definiciones de paisaje que a su criterio eran insuficientes. Su carácter transdisciplinario recibe aportaciones especialmente trascendentales de la geografía y la ecología, con el claro objeto de generar una visión holística de la realidad intentando integrar al máximo su extremada y dinámica complejidad. Incorpora tanto la interpretación de la heterogeneidad horizontal (un enfoque geográfico concentrado en la distribución de los paisajes a lo largo del territorio) como la vertical (una perspectiva propia de la ecología, que enfatiza la interrelación entre los distintos elementos bióticos y abióticos en una porción determinada de paisaje). Evidentemente, la propia dinámica ecológica condiciona los cambios y el dinamismo imperante en la composición estructural y morfológica del paisaje, y ello a su vez está fuertemente teñido de la actividad del hombre, especialmente en los paisajes donde más ha intervenido el mismo. La sociedad termina siendo, en muchos casos, la variable ecológica dominante en la determinación de la configuración del paisaje (Vila Subirós et al., 2006).

Otra disciplina con opinión sobre el paisaje es la agroecología. ${ }^{11}$ Este es un enfoque retomado en los años 70 , pero de ningún modo su práctica y conocimientos son recientes, sino que se remontan a los orígenes de la agricultura. El interés que ha sido redescubierto en estos aportes tiene su raíz en las investigaciones sobre sistemas agrícolas aborígenes, los cuales evidencian la incorporación de mecanismos de adecuación medioambiental en los cultivos y que además implican consideraciones regionales sobre los recursos disponibles. Adquieren relevancia los conceptos y principios ecológicos paisajistas que se suman y enriquecen el enfoque agroecológico, prestando especial atención al proceso de planificación y diseño integral del paisaje (Altieri et al., 1999). La agroecología también pretende, entre otras cosas, participar en el ordenamiento territorial. Aún más, la amalgama con la ecología del paisaje que tiñe este enfoque indica que los procesos agrícolas adquieren peso por su gran impacto en la interacción entre paisajes, actores y sistemas productivos.

Altieri postula que "existen varios temas de investigación sobre el desarrollo, que han sido de especial importancia para la agroecología, incluyendo el impacto de las tecnologías inducidas desde afuera, el cambio de cultivos, los efectos de la expansión de mercados, las implicancias de los cambios de relaciones sociales y la transformación en las estructuras de tenencia de tierra y de acceso a los recursos económicos. Todos estos procesos están íntimamente ligados. Cómo ellos afectan los agroecosistemas regionales es el resultado de complejos procesos históricos y políticos" (Altieri et al., 1999, pp. 27-28). En nuestro país, con respecto a la aplicación de principios agroecológicos en las prácticas agrícolas, existe preocupación porque los productores abandonan el espacio rural para mudarse a las ciudades, desde donde manejan todo a la distancia (en coincidencia con un nuevo modelo territorial emergente tras la reestructuración productiva global). Ello genera inconvenientes: se torna indispensable la presencia de personas en el campo para transmitir conocimientos. El productor es quien mejor conoce sus posesiones, de allí su valor como actor de peso regional.

\subsection{El debate alrededor del Territorio}

La discusión del paisaje lleva a reflexionar en lo que sucede con el territorio que lo contiene. Quizás nos encontramos frente a un actual fenómeno de "multiterritorialización", con "territorios-red" discontinuos y superpuestos, propiciado por la globalización, la hibridación cultural y la fragilidad creciente de fronteras; entonces el desafío se encontraría en avanzar hacia una "conceptualización integradora y contemporánea del territorio" (Haesbaert, 2007). En los últimos treinta años se puede advertir una evolución del pensamiento

\footnotetext{
${ }^{10}$ La disciplina analiza las "características estructurales y morfológicas que componen un territorio en un momento determinado y/o su evolución a lo largo del tiempo, infiriendo a la vez en su incidencia a nivel de funcionalidad ecológica" (Vila Subirós et al., 2006, p. 155).

${ }^{11}$ La misma estudia "fenómenos netamente ecológicos dentro del campo de cultivo" (Altieri et al., 1999, p. 18), con claras raíces ancladas en las ciencias agrícolas, la ecología y el ambientalismo, así como también en las investigaciones sobre desarrollo rural y de agroecosistemas indígenas.
} 
geográfico, de la teoría espacial y de la discusión sobre ordenamiento territorial en un contexto de marcada competitividad, en el cual los territorios deberían indagar en sus roles identitarios para encontrar sus propias claves de desarrollo (Ciccolella, 2006). En este contexto, el proceso reestructurativo capitalista puede ser visto como una totalidad interdependiente en el cual coexisten "lógicas territoriales diferentes", mientras que la economía mundial fija sus raíces en las estructuras territoriales de múltiples maneras, donde lo global se nutre de lo local (Tomadoni, 2007). Se reconoce así un fenómeno de reestructuración productiva ${ }^{12}$ en el que los territorios apelan a su propia historia productiva para atraer capitales transnacionales. La discusión territorial parece ser ahora objeto de interés a nivel nacional.

Es interesante observar que la famosa dicotomía campo-ciudad es en realidad una noción generada desde un pensamiento esencialmente urbano. Tradicionalmente, ha sido desde dicho lugar que se ha mirado al territorio y sus temáticas. En la actualidad, sin embargo, la creciente superación de dicha dualidad no obedecería tanto a razones altruistas, sino más bien a que las ciudades fagocitan territorio a un ritmo cada vez más frenético, y ello ha encendido luces de alarma entre especialistas de disciplinas diversas, pero que tienen un horizonte común: el territorio no puede estar librado a la falta de planificación.

\subsection{Enfoques vinculados al estudio del Territorio}

Toda esta discusión se plasma así en un esfuerzo disciplinar por poner al territorio en el centro del debate, en donde toma fuerza el ordenamiento territorial. ${ }^{13}$ La mirada tradicional sobre la ciudad como objeto final de estudio parece ceder ante una necesidad de entender el contexto que la sostiene (Corboz, 2004). En correlato con esta observación, debería poder superarse la anquilosada dicotomía campo-ciudad, considerando "de manera integral el impacto de la economía sobre los territorios, las percepciones de la población, sus anhelos y sus visiones del mundo, la espacialidad de las infraestructuras y las potencialidades y limitaciones que ofrece el medio ambiente" (Massiris Cabeza et al., 2012, p. 23). El ordenamiento territorial complementa la planificación a nivel socioeconómico, incorporando las dimensiones territorial y ambiental. También se caracteriza por ser prospectivo y democrático: pretende "generar consensos sobre el modelo de ciudad, municipio, departamento o país" que se busca, siempre en el plano colectivo (Massiris Cabeza et al., 2012, p. 23). Podría acotarse, por último, que como instrumento de planificación puede ser enmarcado dentro de una política de Estado, conciliando el desarrollo económico con las formas de ocupación del territorio, y con el claro fin de elevar el nivel de vida humano (Massiris Cabeza, 2005).

A su vez, el resultado lógico de ordenar el territorio debería llevar hacia el proyecto territorial. ${ }^{14}$ Con un enfoque claramente propositivo, se vale de la clave proyectual para poner en valor la dimensión física del territorio. Se le otorgan a la descripción y al análisis territorial atributos propositivos, desdibujando fronteras entre los estudios urbano-territoriales y el proyecto. Interesa reconocer que a las consideraciones sobre la forma del paisaje se les suma la descripción en tanto método explicativo, abriendo el camino hacia una mirada territorial profundamente intencionada que aspira a construir un instrumento de interpretación y un modo renovado de conocimiento. Como expresamos antes al hablar de ordenamiento territorial, los recursos del territorio sintetizan su propia alternativa de futuro, pero esto se torna posible gracias a la descripción, la cual es una herramienta claramente creativa. Dicho componente descriptivo se sustenta en capas (o lecturas) que desglosan minuciosamente la

\footnotetext{
12 Proceso que implica el paso de una sociedad industrial a una post-industrial, donde el sector terciario se expande a costa del secundario. Se caracteriza por: niveles crecientes de educación y formación profesional especializada exigidos por el mercado laboral; una organización aún más compleja tanto de las formas económicas como de gobierno; una expansión de las fronteras espaciales y cognitivas dentro de las cuales tienen lugar las transacciones económicas y sus consecuencias sociales; se consolidan la flexibilización tanto laboral como de las formas de producción; se conforman entes a nivel regional como estrategia territorial para competir interterritorialmente; entre otros (Tomadoni, 2007).

13 "Proceso de carácter técnico-político-administrativo con el que se pretende configurar, en el largo plazo, una organización del uso y ocupación del territorio, acorde con las potencialidades y limitaciones de este, con las expectativas y las aspiraciones de la población y con los objetivos de desarrollo. El ordenamiento territorial se concreta en planes que expresan el modelo territorial de largo plazo que se pretende lograr y las estrategias mediante las cuales se actuará sobre la realidad para evolucionar hacia dicho modelo" (Massiris Cabeza, 2005, pp. 15-16).

14 "Los criterios e instrumentos de transformación territorial, así como los métodos de intervención, subyacen embrionariamente desde las primeras lecturas del territorio, ya que un reconocimiento atento del mismo pone en relieve su vocación y las claves de su reproposición" (Díaz Terreno, 2013, p. 24). La observación morfológica territorial, así como su descripción, conducen a repensar el paisaje en cuanto valor estético. Se pueden encontrar nuevos vínculos entre plan y proyecto (y entre urbanismo y pieza arquitectónica) al dotar a la forma territorial de una importancia y estatuto particulares (Díaz Terreno, 2013).
} 
forma y estructura territorial, considerando así sus actividades económicas, asentamientos, trazados e infraestructuras, así como la matriz ambiental, el sistemas de espacios abiertos y el soporte de la movilidad.

También desde la etnografía se postulan ideas sobre el discurso cultural sobre el soporte territorial: así, narrar la historia de un territorio y de sus actores puede hilarse desde la descripción densa. ${ }^{15}$ Al respecto, "la cultura es un contexto dentro del cual pueden describirse todos esos fenómenos de manera inteligible, densa" (Geertz, 1973, p. 27). El enfoque etnográfico no puede escindirse del contexto y de los diversos significados de sus relaciones: la única manera de estudiar la cultura y sus manifestaciones es dentro de dicho contexto propio (Díaz Terreno, 2013).

Por último, tratando de generar un aporte al entendimiento y posterior síntesis y eventual proyectación sobre el territorio, es que se ubica el enfoque regional del patrimonio. ${ }^{16}$ El enfoque se encuadra en el marco de la planificación urbano-regional, valorando particularmente el patrimonio urbano-arquitectónico (Foglia \& Goytía, 1993). Se persigue descubrir y poner en conocimiento ciertos componentes físicos construidos del territorio, que "pudiesen reunir valores patrimoniales: poblados, caseríos, piezas arquitectónicas aisladas y algunas vías de comunicación" (Díaz Terreno, 2013, p. 20). Se intentan juntar así "otros abordajes provenientes de la planificación regional y de la valoración del patrimonio arquitectónico". Los pequeños centros urbanos eran estudiados desde la planificación, mientras que monumentos, tejido urbano y la escala de ciudad eran abordados desde enfoques históricos, y por último, la perspectiva regional ayudó a comprender el "conjunto del sistema de centros urbanos emergente de procesos de ocupación comunes, vinculados entre sí por ciertas trazas de trayectos recorribles, pero también por cierto grado de homogeneidad de comportamiento según su tamaño y función" (Díaz Terreno, 2013, p. 21). Lo que entonces fue puesto en evidencia no fue otra cosa que una organización territorial a la manera de un sistema urbano regional al reconocer dichos componentes y su articulación a través de recorridos e itinerarios (con claros paralelismos con los trabajos de paisaje cultural en gestación en otros lugares del mundo).

\subsection{Estrategia metodológica emergente}

Ahora bien, ¿cómo valerse de las distintas experiencias y conocimientos que estos enfoques postulan para aplicarlos en una metodología ajustada a los requerimientos de este trabajo? ¿En qué punto pueden integrarse dichos abordajes en la investigación y dar lugar a un rearmado propio? ¿Qué resulta más útil y qué puede ser reinterpretado según los propios objetivos doctorales? Todos ellos son interrogantes que guiaron el armado de la estrategia metodológica resultante para este trabajo. A su vez, cada objetivo particular agrupa contenidos que se busca cumplir a través del uso de diferentes métodos. Allí es donde se tornan evidentes las aportaciones agrupadas en torno al paisaje cultural y al ordenamiento territorial. Comentaremos a continuación cómo se reflejan esas influencias en las estrategias metodológicas planteadas para cada objetivo específico de esta investigación, ejemplificando gráficamente con el mapa de la investigación correspondiente a cada uno de ellos.

Para el Objetivo 1, son recabados datos sobre el soporte físico-territorial de la CLCA. Las fuentes son primarias (incluyendo entrevistas a personajes y agentes pertinentes) así como documentales (cartografía y fotografías aéreas y satelitales). Se analizan así las características naturales y la morfología del territorio. Se pretende rescatar la mirada de la ecología del paisaje en este reconocimiento físico del territorio. Básicamente, se trata de fundamentar la forma de trabajo en una lectura gráfica intencionada, en sucesivas escalas de aproximación y en capas superpuestas, para luego poder interpretar/valorar. De este modo, la gráfica no es usada sólo para describir, sino que es una herramienta de diagnóstico y de proposición en sí misma. Se alude a la forma de mirar el territorio y sus componentes, los cuales sólo son descubiertos al cambiar sucesivamente de escalas. Las capas implican una lectura a través de subsistemas de componentes que se agrupan y que, al ser superpuestos, brindan la posibilidad de obtener conclusiones al entrecruzar variables de cada uno de ellos.

\footnotetext{
${ }^{15}$ La misma resulta interpretativa del flujo del discurso social, tratando de rescatar "lo dicho" en dicho discurso de sus ocasiones perecederas y fijándolo en términos susceptibles de consulta (Geertz, 1973, p. 27). Se rescata de esta manera el carácter interpretativo fenomenológico y los rasgos o aspectos de una circunstancia particular (Díaz Terreno, 2013).

${ }^{16} \mathrm{Sin}$ embargo, el mismo autor reconoce las limitaciones del enfoque al plantear que el alcance se centra en la escala urbana, y no en la forma detallada del territorio. La forma del territorio estaría reclamando con fuerza su valor como "factor explicativo de las estrechas relaciones entre el soporte natural y modos de ocupación, en ese proceso dialéctico de adecuaciones mutuas entre mandatos culturales y realidad geográfica específica" (Díaz Terreno, 2013, pp. 22-23).
} 
Luego se analizan datos sobre el poblamiento humano del área: centros urbanos y su entorno rural son estudiados recurriendo al relevamiento de campo (fotografías y croquis) y documental (imágenes satelitales, cartas topográficas, planes municipales) mapeando expresiones de cinturones verdes, bordes urbano-rurales y corredores ecológicos. Se busca comprender las lógicas y formas de ocupación histórica del territorio y las huellas de la explotación productiva sobre el mismo: una mirada que se trasluce en esta etapa de estudio de los centros urbanos es la del enfoque regional del patrimonio.

Finalmente, se estudia en profundidad el componente antrópico. Se incluyen observaciones participantes (asistiendo a fiestas populares del nutrido calendario local) para obtener datos sobre el patrimonio cultural no tangible. Se conforman grupos de discusión en el sitio que contemplen la participación de diversos actores sociales. Otras fuentes de información primaria provienen de entrevistas semiestructuradas dirigidas a personajes de la cultura, así como la recopilación de historias de vida o testimonios de personas que residen en la región. Se pretende, una vez recabada y procesada toda esa información, narrar una historia detallada del territorio estudiado para así poder entender su actual estructura. En este punto es posible reconocer lecciones de la descripción densa. La estructura narrativa que surge de esta etapa es de mucha importancia, porque le da a la investigación la dimensión perceptual y subjetiva que tienen sobre el territorio sus propios habitantes, y que permite incorporar al tiempo como componente en la confección de una historia territorial local.

\begin{tabular}{|c|c|c|c|c|}
\hline OBJETIVO & CAPITULO & CONTENIDOS & CATEGORIAS CONCEPTUALES & ENFOQUES \\
\hline $\begin{array}{l}\text { 1. Historizar y analizar el } \\
\text { proceso do construccion } \\
\text { del paisaje de ta CLCA a } \\
\text { partir del reconocimiento de }\end{array}$ & $\begin{array}{l}\text { 2. CONSTRUCCION } \\
\text { FISICA DEL } \\
\text { TERRITORIO }\end{array}$ & $\begin{array}{l}\text { "Caracterización del soporte natural de } \\
\text { la CLCA y de sus componentes fícicos } \\
\text { (clima, geomortologia, hiscrologia, flora } \\
\text { y fauna) }\end{array}$ & $\begin{array}{l}\text { TERRITORIO } \\
\text { "Soporto Nafural } \\
\text { "Espacio Natural } \\
\text {-Patrimonio Natural }\end{array}$ & "ECOLOGIA DEL PAISAJE \\
\hline $\begin{array}{l}\text { las improntas nafurales y } \\
\text { antropicas que definen nu } \\
\text { estructura territorial y que } \\
\text { conithbuyeron a consiruir-sut } \\
\text { actual confouracion. }\end{array}$ & $\begin{array}{l}\text { 3. CONSTRUCCION } \\
\text { SOCIOCULTURAL } \\
\text { DEL TERRITORIO }\end{array}$ & 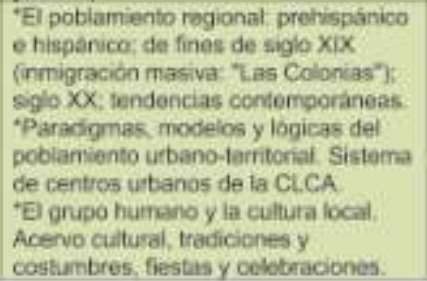 & $\begin{array}{l}\text { "Lojocas de Ocupacion } \\
\text { "Modelos de Orden Terntorial } \\
\text { "Recurso Cultural } \\
\text { "identidad Cuitural } \\
\text { 'Patrimonio Cultural }\end{array}$ & $\begin{array}{l}\text {-ENFOOUE REGIONAL DEL } \\
\text { PATRIMONIO } \\
\text { 'DESCRIPCION DENSA }\end{array}$ \\
\hline
\end{tabular}

Figura 3. Mapa de la investigación: fracción síntesis correspondiente al Objetivo 1, remarcando los enfoques incluidos.

Fuente: elaboración propia.

Para el Objetivo 2, se recolectan datos sobre la actividad productiva en general (y lechera en particular) de la CLCA para ser analizados y contrastados con información de otras cuencas (nacionales y extranjeras). Las fuentes son, por un lado, primarias (se planea realizar entrevistas semiestructuradas a diferentes agentes, así como a personal del INTA), y secundarias (censos sobre actividad productiva, informes y diagnósticos ya elaborados por organismos y especialistas pertinentes, cartografía e imágenes satelitales, directorios y guías específicas). Se busca entender la actividad lechera en el marco de la problemática global de reestructuración productiva.

Es fundamental para esta investigación conocer en profundidad las actividades productivas y su impacto en el territorio, ya que de ello se desprende su configuración paisajística. Pero también se reivindica en este momento la mirada de la agroecología en el estudio de las relaciones entre actividades productivas y el componente ecológico del territorio abordado. Si consideramos que la dimensión de la sostenibilidad está implícita en esta lectura, entonces las enseñanzas y postulados de la agroecología en la valoración de las actividades productivas será fundamental para llegar luego al objetivo final de la investigación, en la cual se pretende generar una síntesis propositiva con alternativas de desarrollo regional para el territorio estudiado. Se utilizan en esta etapa técnicas cualitativas como la investigación documental. 


\begin{tabular}{|c|c|c|c|c|}
\hline OBJETIVO & CAPITULO & CONTENIDOS & CATEGORIAS CONCEPTUALES & ENFOOUES \\
\hline 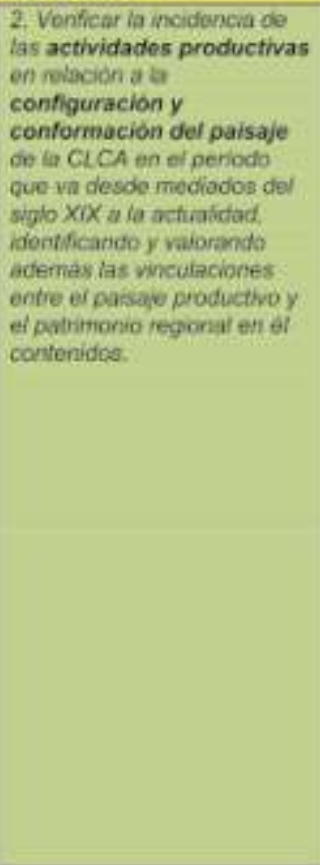 & $\begin{array}{l}\text { 4. EL. TERRITORIO } \\
\text { PRODUCTIVO }\end{array}$ & 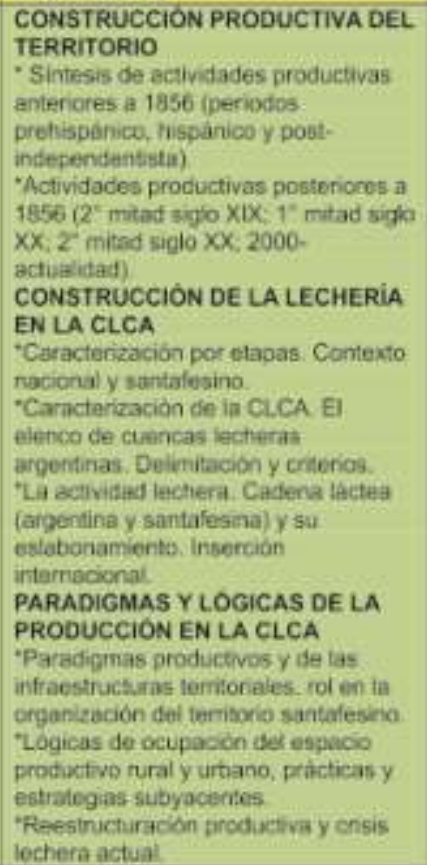 & $\begin{array}{l}\text { "ACTIVIDAD PRODUCTIVA } \\
\text {-Cuencir Productiva } \\
\text { "Espacio Rural } \\
\text {-Paisaje Productivo } \\
\text {-Paisaje Fentroviario } \\
\text { "Pampa }\end{array}$ & $\begin{array}{l}\text { "RURALISTICA } \\
\text { 'ARQUEOLOGIA DEL } \\
\text { PAISAJE }\end{array}$ \\
\hline
\end{tabular}

Figura 4. Mapa de la investigación: fracción síntesis correspondiente al Objetivo 2, remarcando los enfoques incluidos. Fuente: elaboración propia.

Para el Objetivo 3, se redefine en primera instancia el concepto de paisaje según los fines y posicionamiento perseguidos en la investigación. Se selecciona casuística particularizada relativa a referentes de paisajes desde el relevamiento de campo tanto en Europa como en el medio local, y también a través de análisis documental sobre otros ejemplos. De este modo, se confecciona una propia matriz de datos y de variables que pueden ser extrapolables a la CLCA. Se catalogan atributos y elementos locales a partir de la recopilación y el mapeo natural y antrópico del territorio. Se definen variables propias, estableciendo categorías y grupos específicos para el caso de estudio, para finalmente valorar el patrimonio emergente y su dinámica. Identificar los componentes del paisaje permite luego integrarlos en un diagnóstico paisajístico. En todas estas actividades, nuevamente, aparecen postulados y enseñanzas de las experiencias de paisaje cultural.

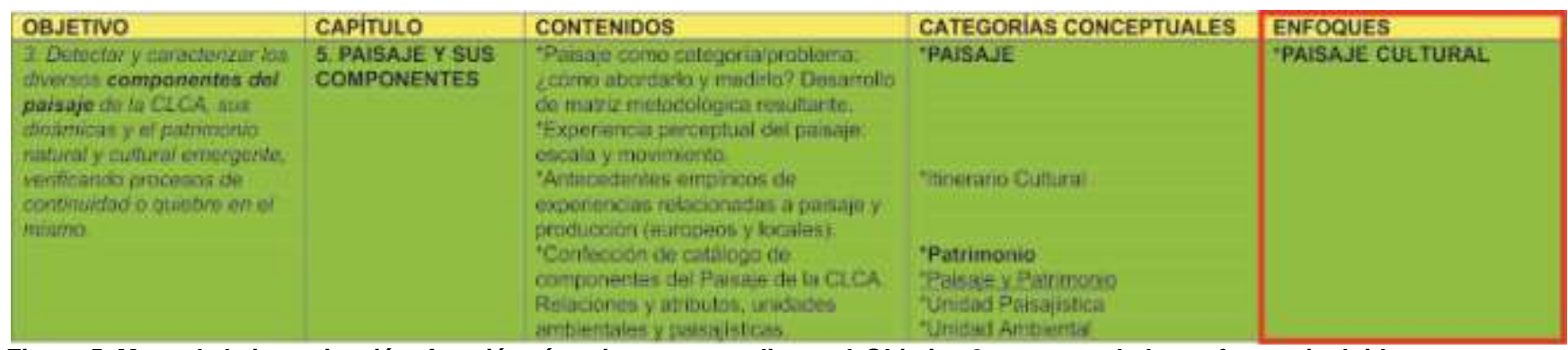

Figura 5. Mapa de la investigación: fracción síntesis correspondiente al Objetivo 3, remarcando los enfoques incluidos.

Fuente: elaboración propia.

Para el Objetivo 4, que coincidirá finalmente con una definitiva instancia de trabajo, se recurrirá a la información elaborada en objetivos anteriores con el objeto de entrecruzar y comprender las relaciones entre las actividades productivas, el paisaje, el patrimonio, la problemática ambiental y la sociedad local. Se recopilarán datos documentales (planes de ordenamiento multiescalares) para analizar la normativa vigente, sus aportes, falencias y vacíos, y las consecuencias que ello acarrea para la CLCA. La meta será formular una síntesis ajustada para el paisaje estudiado, arribando a las conclusiones finales de este trabajo. Dicha síntesis se realizará de manera gráfica (a través de mapas, cartografía, croquis, perspectivas e imágenes que sean consideradas necesarias) como escrita (redactando lineamientos y recomendaciones), y expresando un modelo paisajístico-territorial deseable para la CLCA. Coincidirán en este momento no sólo una revisión de los métodos 
y contenidos aplicados anteriormente y condensados en torno al ordenamiento territorial, sino que además, al avanzar en lineamientos y sugerencias regionales, aparecerá en el centro de la escena el proyecto territorial.

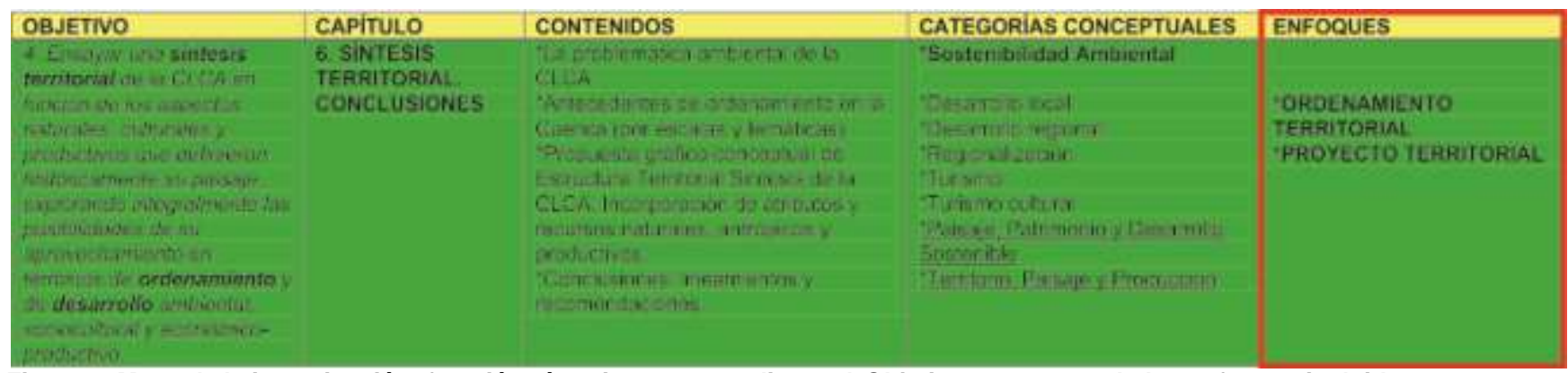

Figura 6. Mapa de la investigación: fracción síntesis correspondiente al Objetivo 4, remarcando los enfoques incluidos.

Fuente: elaboración propia.

\subsection{Ensayo metodológico: Cinque Terre como antecedente casuístico}

Estudiar casuística sobre experiencias de paisajes e itinerarios culturales es parte del Objetivo 3 de esta investigación doctoral. Uno de los casos estudiados corresponde al de Cinque Terre en Liguria, Italia. De entre la casuística europea abordada, se trata del ejemplo del que disponemos de más información. Esto se debe no sólo a que es un caso largamente documentado y de amplia promoción turística en diversas, sino al trabajo de campo que tuvimos oportunidad de realizar en el sitio en 2016, aprovechando la estadía doctoral en Europa. Para dicha visita se diseñó previamente una estrategia metodológica con el claro objeto de recabar datos que respondieran a variables específicas. Para facilitar la tarea, se definieron las fuentes desde donde se obtendrían los datos deseados. Así, se realizó un cuadro metodológico para recopilar tanto información de fuentes secundarias (previo al viaje) como de fuentes primarias (trabajo de campo). Todo ello se grafica en la Figura 7.

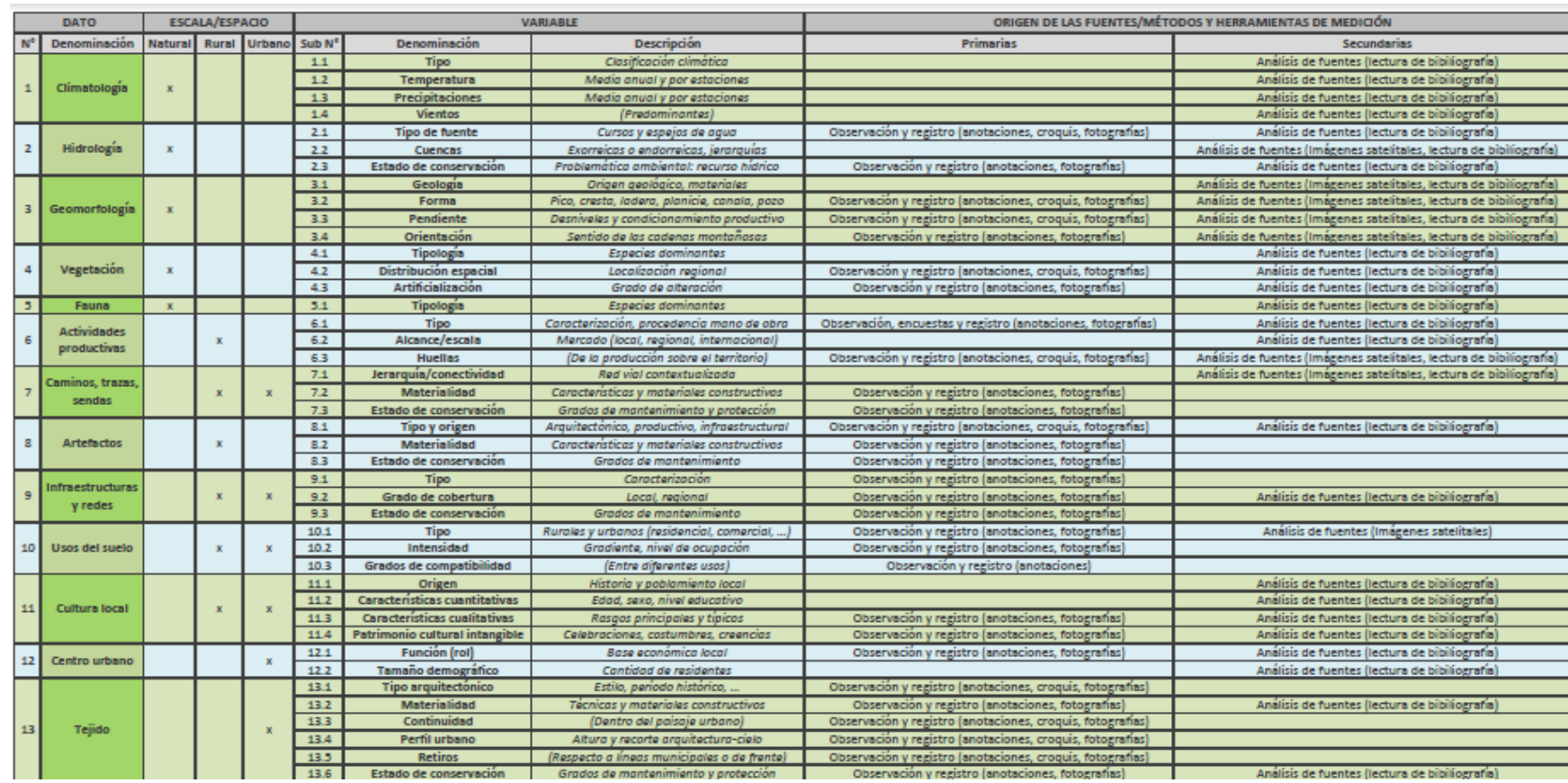

Figura 7. Parte del cuadro metodológico diseñado para recopilación de datos sobre el paisaje cultural de Cinque Terre, Italia.

Fuente: elaboración propia.

La información a colectar abarcaba los siguientes aspectos: climatología, hidrología, geomorfología, vegetación, fauna, actividades productivas, caminos, artefactos (arquitectónicos, productivos o infraestructurales), infraestructura y redes, usos del suelo (incluyendo al espacio público), cultura local, centro urbano, tejido, hitos, nodos, bordes, puertas, y visuales. Entre las herramientas utilizadas para recabar los datos primarios se encuentran la observación y el registro (anotaciones, croquis, fotografías), mientras que para el análisis de 
fuentes secundarias se realiza lectura de bibliografía y la búsqueda de imágenes satelitales. Los resultados del registro in situ pueden visualizarse en la Figura 8.

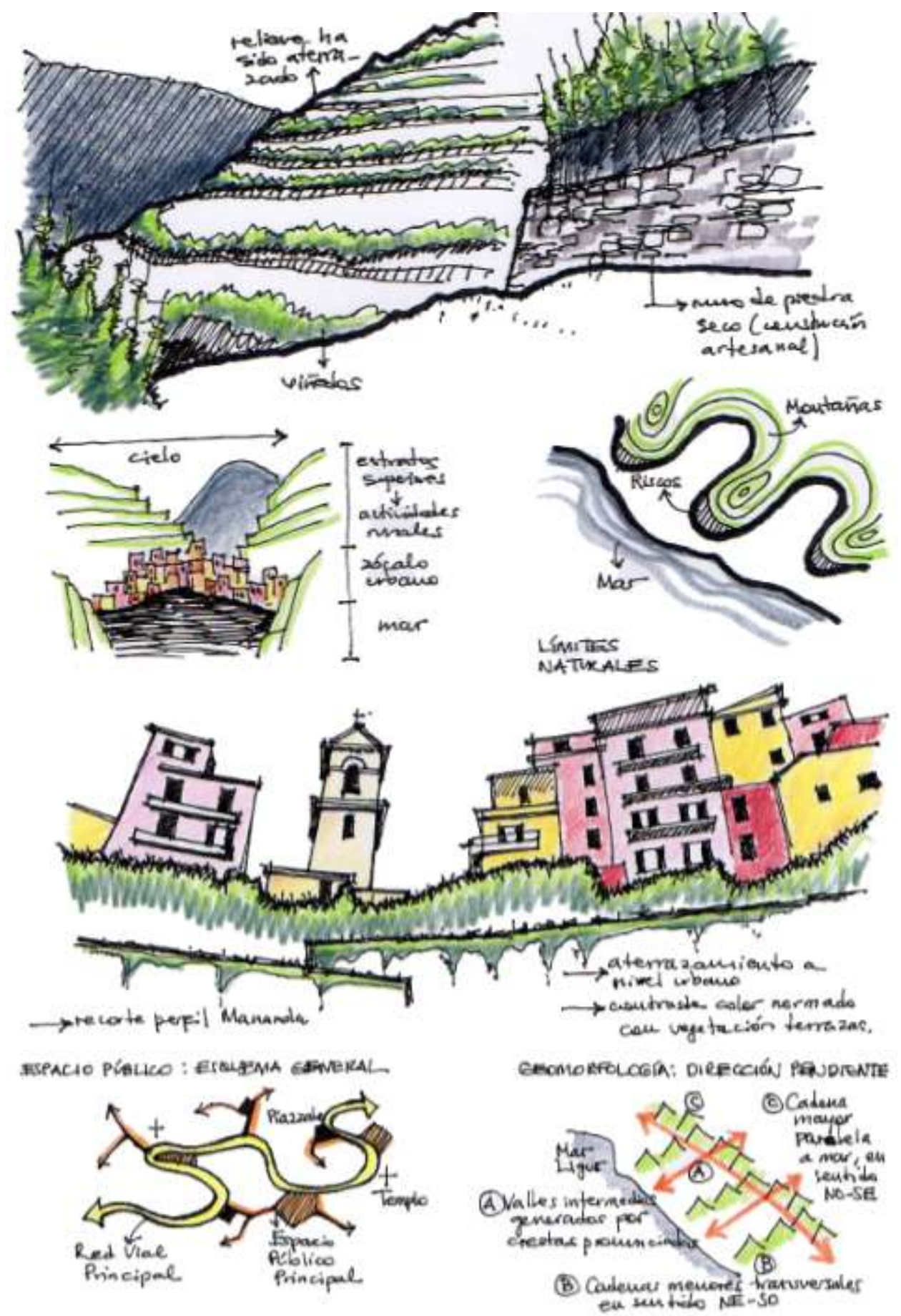

Figura 8. Relevamiento de componentes paisajísticos en ocasión de la visita de campo a Cinque Terre, Italia. Fuente: elaboración propia.

Cinque Terre fue declarado Patrimonio Mundial de la Humanidad en 1997, mientras que en 1999 adquiere estatus de Parque Nacional. Por ello es que al momento de realizar la visita en 2016, se diseñaron un par de entrevistas semiestructuradas, una dirigida a productores locales, la otra a agentes estatales ligados al Parque Nacional. El resultado de esta estrategia podría definirse como mixto, ya que sólo un productor accedió a 
realizar la entrevista, mientras que por motivos logísticos y de tiempo y espacio no se pudo dar dicha oportunidad con otros empresarios y con los agentes del Estado previamente contactados. Para nuestra sorpresa y enorme satisfacción, sin embargo, el Señor Buranco (quien accedió a ser visitado) no sólo contestó las preguntas sino que además brindó otros datos que no estaban previstos, los cuales se relacionan a experiencias de vida y a percepciones sobre la actividad, el territorio, el paisaje y el propio lugar en el mundo.

En la historia de vida del Señor Buranco aparecieron algunas frases muy interesantes, en cuanto a significado y en lo que a síntesis se refiere. Por un lado, en Cinque Terre, cuando muere un anciano, "muere un pedazo de tierra", porque ellos son parte de la misma, "aficionados" y apasionados que la trabajan casi sin descanso. Por otra parte, los productores son los "jardineros del paisaje", manteniendo un sistema ancestral de cultivo y producción que no sólo embellece y le da un carácter único al paisaje, sino que además son los encargados de detener y contener las aguas de lluvia, que de otra manera arrasarían con las poblaciones cuesta abajo. En otras palabras, confirmaría que un paisaje cultural no es otra cosa que un "memorial al trabajador desconocido" (Martínez de San Vicente \& Sabaté Bel, 2010, p. 140). El caso de Cinque Terre, más allá de las diferencias y distancias, posee para esta investigación el valor de revelar la triada territorio-paisaje-producción de manera muy directa, con la posibilidad además del ensayo de métodos y la extracción de conclusiones parciales que ayuden al rediseño metodológico.

\section{ALGUNAS REFLEXIONES}

Rescatar la importancia de los enfoques que dialogan sobre los conceptos fundamentales que se tocan en la investigación y entender desde qué lugar discursivo e incluso ideológico se construyen dichas miradas es clave para autoposicionarse en la conversación. Del mismo modo, las aportaciones diversas permiten tomar sus experiencias y saberes para luego ser creativo en su empleo y resignificación. Son los objetivos que emanan de la hipótesis principal los que deben guiar la búsqueda de técnicas y estrategias metodológicas para encarar la investigación, y nunca al revés.

Encontrar puntos de contacto entre expresiones de la ruralística, los paisajes culturales, la antropología del paisaje o la ecología del paisaje debiera ser una prioridad para no perder de vista que el objeto de estudio es el resultado de la interacción compleja entre varios factores y actores a lo largo de un tiempo y espacio únicos. Tejer historias para conocer profundamente la realidad territorial parece ligar a la descripción densa y al enfoque regional del patrimonio, mientras que el ordenamiento y el proyecto territorial, con una visión quizás holística, pretenden retomar los recursos enumerados en dichas historias al servicio de un futuro pensado y consensuado, incierto pero ante el cual se podría operar con criterios planificados.

El debate resalta roles y papeles, la importancia del paisaje en tanto recurso finito que debe ser estudiado y administrado, y el posicionamiento frente a la problemática ambiental y económica actual. En dicho marco, adquiere especial relevancia la discusión que relaciona territorio y paisaje a desarrollo local: la propia historia productiva como alternativa de lo local frente a lo global. En un contexto de crisis y recesión económica mundial, afloran las oportunidades en tanto se es creativo y se apuesta por las fortalezas locales y se trabaja sobre las debilidades regionales.

Finalmente, territorio y paisaje parecen ser una unidad indisoluble en el tiempo-espacio: uno sustenta y provee, el otro expresa sus marcas visibles. Un binomio que revela los manejos y desmanejos del ser humano con los recursos que ha encontrado en la naturaleza y que ha reclamado, apropiado, construido y destruido para sí. Porque parece claro que no hay paisaje sin personas que lo perciban y lo vivencien, pero tampoco hay territorio sin paisaje que lo traduzca y lo resemantice.

\section{REFERENCIAS BIBLIOGRÁFICAS}

Altieri, M. A., Hecht, S., Liebman, M., Magdoff, F., Norgaard, R., \& Sikor, T. O. (1999). Agroecología: bases científicas para una agricultura sustentable. Editorial Nordan-Comunidad. Montevideo.

Argos Proyectos Educativos S.L. (2009). Manual de Integración Paisajística. Parque Natural de Sierra Norte. (Argos Proyectos Educativos S.L., Ed.). El Adalid Seráfico, S.L.L. Recuperado a partir de https://www.juntadeandalucia.es/medioambiente/portal_web/web/temas_ambientales/paisaje/4_planificaci on/manual_integracion_paisajistica.pdf 
Ciccolella, P. (2006). Economía y espacio. Ejes de discusión para un desarrollo territorial más allá de la globalización. Párrafos Geográficos, 5(nْ1). Recuperado a partir de http://igeopat.org/revista/images/RevistasPG/2006_V5_1/5-1.pdf

Corboz, A. (2004). El Territorio como Palimpsesto. En Lo urbano en 20 autores contemporáneos (pp. 25-34). Barcelona: Departamento de Urbanismo y Ordenación del Territorio, UPC.

Cosgrove, D. (2002). Observando la Naturaleza: El Paisaje y el Sentido Europeo de la Vista. Boletín de la Asociación de Geógrafos Españoles, (34), 63-89. https://doi.org/ISSN 0212-9426

Díaz Terreno, F. (2013). Constelaciones Rurales Serranas. Lógicas de Ocupación del Territorio y Modelos de Orden. Lecturas interpretativas de la construcción histórica del Norte de Traslasierra, Córdoba, Argentina. Universidad Politécnica de Cataluña.

Foglia, M. E., \& Goytía, N. (1993). Los Poblados Históricos del Norte Cordobés. Córdoba: Secretaría de Turismo de la Provincia de Córdoba.

Geertz, C. (1973). Descripción densa: hacia una teoría interpretativa de la cultura. En La interpretación de las culturas (1992. ${ }^{a}$ ed., pp. 1-387). Barcelona. https://doi.org/10.1017/CBO9781107415324.004

González Villaescusa, R. (1996). Arqueología del paisaje e historia agraria: algunas cuestiones de método. Revista de Historia Medieval, 7, 223-242. https://doi.org/10.1192/bjp.76.313.339-a

Haesbaert, R. (2007). O mito da desterritorialização: do «fim dos territórios» à multiterritorialidade. Ensaios sobre o ordenamento territorial. Recuperado a partir de http://books.google.com/books?ei=vh4xUvbFHoW09gTRo4HIBg\&hl=pt-BR\&id=sEkSAQAAIAAJ\&pgis=1

Martínez de San Vicente, I., \& Sabaté Bel, J. (2010). Apuntes metodológicos en la ordenación de paisajes culturales: el caso de la Quebrada de Humahuaca, 22(2009), 139-157.

Massiris Cabeza, Á. (2005). Fundamentos conceptuales y metodológicos del Ordenamiento Territorial. Tunja, Boyacá.

Massiris Cabeza, Á., Espinoza Rico, M. A., Ramírez Castañeda, T., Rincón Avellaneda, P., \& Sanabria Artunduaga, T. (2012). Procesos de ordenamiento en América Latina y Colombia. Bogotá: Acción Gráfica Editores.

Nogué, J. (2007). Territorios sin discurso, paisajes sin imaginario. Retos y dilemas. Ería: Revista cuatrimestral de Geografía, (73-74), 373-382. Recuperado a partir de http://www.revistaeria.es/index.php/eria/article/viewArticle/731

Sabaté Bel, J. (2003). Balance y perspectivas del planeamiento urbanístico municipal. En Planeamiento urbanístico. De la controversia a la renovación (pp. 181-204). Barcelona: Diputación de Barcelona.

Sabaté Bel, J. (2010). De la preservación del patrimonio a la ordenación del paisaje: intervenciones en paisajes culturales (Europa - Latinoamérica). Labor \& Engenho, 4(1), 10-25.

Tomadoni, C. (2007). Cidades (pós)industriais na Alemanha (pós)unificada: encolhimento e suburbanização. Geografias. Departamento Geografia e do Programa de Pós-graduação em Geografia da Universidade Federal de Minas Gerais, 3(2), 54-71.

Vila Subirós, J., Varga Linde, D., Llausàs Pascual, A., \& Ribas Palom, A. (2006). Conceptos y métodos fundamentales en ecología del paisaje (landscape ecology). Una interpretación desde la geografía. Documents d'Analisis Geogràfica, 48, 151-166. 